\title{
Research on the Communication Power of Historical and Cultural Omnimedia Platform
}

\author{
Hong Yan Cong ${ }^{1 *}$, Jue Wen $\mathrm{Li}^{2}$, Dong $\mathrm{Ma}^{3}$ \\ ${ }^{1}$ School of New Media Art, Xi 'an Polytechnic University, Xi 'an, Shaanxi,710048, China. \\ ${ }^{2}$ School of New Media Art, Xi 'an Polytechnic University, Xi 'an, Shaanxi,710048, China. \\ ${ }^{3}$ School of New Media Art, Xi 'an Polytechnic University, Xi 'an, Shaanxi,710048, China. \\ *Corresponding author. Email: 820760223@qq.com
}

\begin{abstract}
Under the background of informatization wave, the audience's thirst for historical and cultural knowledge highlights the importance of popularization of science. It is urgent to clarify the content, form and effect of the dissemination through data analysis, so as to facilitate the popularization of science of history and culture. Based on the historical and cultural media in WeChat, client and trill of all media, as an example, through the summary account data information, analysis of three different media vehicles in such aspects as content, form and effect of the spread of the status quo, booster "a micro end a shake" spread pattern formation, strengthen all of the historical and cultural media media propagation force.
\end{abstract}

Keywords: History and culture, Omnimedia platform, The propagation force

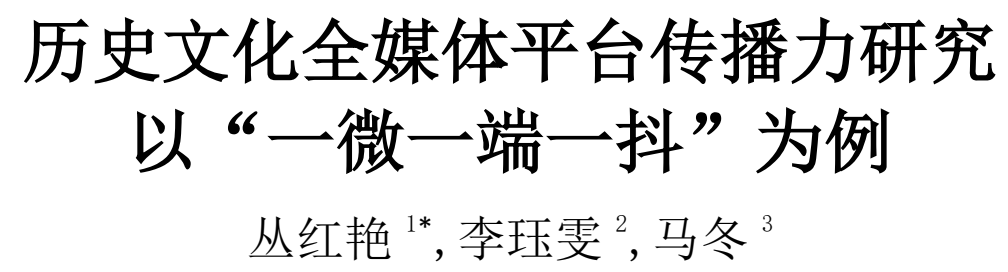

${ }^{I}$ 西安工程大学新媒体艺术学院, 陕西西安, 710048, 中国

2 西安工程大学新媒体艺术学院, 陕西西安, 710048, 中国

${ }^{3}$ 西安工程大学新媒体艺术学院, 陕西西安, 710048, 中国

“通讯作者. 由箱: 820760223@qq. com

\section{摘要:}

信息化浪潮背景下, 受众对历史文化知识的渴求彰显出其科普传播的重要性，亟须通过数据分析厘清其传播内 容、形式和效果，助力历史文化的科普传播。本文以历史文化类媒体在微信、客户端以及抖音的全媒体传播为 例, 通过汇总账号数据信息, 分析三种不同媒介载体在内容、形式和效果等方面的传播现状, 助推 “一微一端 一抖”传播格局的形成，加强当下历史文化类媒体的全媒体传播力。

关键词: 历史文化; 全媒体平台; 传播力

\section{1. 前言}

数字化已经紧紧地与我们的生活联系在一起, 知 识的获取形式由传统的书本、报纸等形式变为网络获 取的形式。伴随着智媒时代的快速传播, 历史文化热 潮使得公众对于历史信息的关注度不断加强。微信公 众号、网站客户端以及抖音逐渐成为其发展的平台,
形成了“一微一端一抖”的全媒体传播格局。

\section{2. 历史文化类微信公众号分析}

\section{1. 历史文化类微信公众号发展现状}

国家因文化而繁荣，文化因流动而具有活力。智 媒时代, 微信已成为历史文化传播的重要突破口之一。 
在受众接受信息的环境更为碎片化的今天，历史文化 微信公众号的发展逐渐将历史文化信息带入全媒体
时代下的传播浪潮中, 成为全媒体传播过程当中的重 要一环，不断推动形成历史文化全媒体传播格局。

表 1 历史文化类微信公众号现状分析

\begin{tabular}{|c|c|c|c|c|}
\hline 名称 类别 & 平台建设 & 推文内容 & 导航栏 & $\begin{array}{l}\text { 互动性 } \\
\text { ( 预估活跃粉 } \\
\text { 丝数 ) }\end{array}$ \\
\hline 国家人文历史 & $\begin{array}{c}\text { 人民日报社主管主办，原名《文 } \\
\text { 史参考》，为学术界搭建话语平 } \\
\text { 台，为新锐者提供思想阵地，为 } \\
\text { 文史爱好者营造精神家园。 }\end{array}$ & $\begin{array}{l}\text { 肺炎专题 } \\
\text { 史家谈兵 } \\
\text { 人文地理 } \\
\text { 国际风云 }\end{array}$ & $\begin{array}{c}\text { 专题文章 } \\
\text { 果粒历史 } \\
\text { 客服 }\end{array}$ & 631937 \\
\hline 最爱历史 & $\begin{array}{c}\text { 知名文史作家， } 2018 \text { 年度 U 创 } \\
\text { 大奖得主，只做深度+原创好 } \\
\text { 文，在这里遇见不一样的历史。 }\end{array}$ & $\begin{array}{l}\text { 历史音频 } \\
\text { 隋唐往事 } \\
\text { 两宋风云 } \\
\text { 大明兴亡 }\end{array}$ & $\begin{array}{l}\text { 逛逛小店 } \\
\text { 音频入口 } \\
\text { 欢迎来撩 }\end{array}$ & 990639 \\
\hline 短史记 & $\begin{array}{c}\text { 原创栏目《短史记》疑今察古 鉴 } \\
\text { 往知来 }\end{array}$ & $\begin{array}{l}\text { 历史典故 } \\
\text { 文化知识 } \\
\text { 科普历史 }\end{array}$ & $\begin{array}{l}\text { 编辑推荐 } \\
\text { 热文推荐 } \\
\text { 布谷学社 }\end{array}$ & 519283 \\
\hline 读书人冯学荣 & $\begin{array}{l}\text { 著有《隐动力》、《中国历史的侧 } \\
\text { 面 II》《不忍面对的真相》等 }\end{array}$ & $\begin{array}{l}\text { 科普历史 } \\
\text { 时事评论 } \\
\text { 历史故事 }\end{array}$ & $\begin{array}{l}\text { 加入圈子 } \\
\text { 精彩文章 }\end{array}$ & 706244 \\
\hline 历史研习社 & $\begin{array}{c}\text { 顺时针研究历史，逆时针解毒世 } \\
\text { 界 }\end{array}$ & $\begin{array}{l}\text { 考古知识 } \\
\text { 科普 } \\
\text { 历史文化 } \\
\text { 影视 } \\
\text { 科普历史 }\end{array}$ & $\begin{array}{c}\text { 听节课 } \\
\text { 选好书 } \\
\text { 加入我社 }\end{array}$ & 850806 \\
\hline 中华书局 & $\begin{array}{l}1912 \text { 年建立，在历经百年之后依 } \\
\text { 然充满了社会责任感和使命感， } \\
\text { 用文化来表达对文明的信仰，让 } \\
\text { 读者可以一同感受到书中带来的 } \\
\text { 文化智慧和深刻内涵。 }\end{array}$ & $\begin{array}{l}\text { 图书推荐 } \\
\text { 名著解说 } \\
\text { 新书简介 }\end{array}$ & $\begin{array}{l}\text { 读者服务 } \\
\text { 专题书单 } \\
\text { 读点什么 }\end{array}$ & 174292 \\
\hline 文博中国 & $\begin{array}{l}\text { 中国文物报社是国家文物局主管 } \\
\text { 的文博考古全行业权威媒体单 } \\
\text { 位，文博中国为创立最早、重要 } \\
\text { 的官方新媒体平台。 }\end{array}$ & $\begin{array}{l}\text { 考古知识科普 } \\
\text { 文物科普 } \\
\text { 考古界时事 }\end{array}$ & $\begin{array}{l}\text { 评选推荐 } \\
\text { 联系我们 }\end{array}$ & 40130 \\
\hline
\end{tabular}




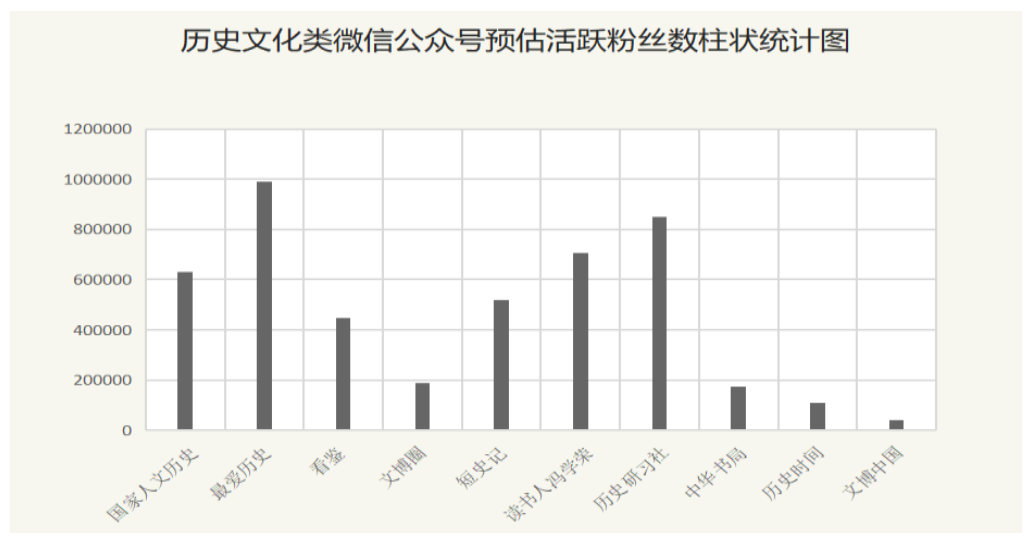

图 1 历史文化类微信公众号预估活跃粉丝数柱状统计图

\section{2. 历史文化类微信公众号传播力研究}

\subsection{1. 传播形式}

其一，稳固推文频率，聚焦受众群体。即使内容 为王的理念在微信公众号的信息传播中起关键性作 用，但是稳定推文时间和频率也是聚焦受众群体的途 径之一。当前, 历史文化类微信公众号普遍存在着推 文时间间隔较长，推送内容毫无法则的问题。微信公 众号活跃度总体偏低。碎片化的推送时间不能聚集受 众的注意力, 容易导致造成关注力的过度分散。因此, 需遵循注意力经济下的吸引力法则, 通过固定的推送 时长培养受众的阅读习惯和忠诚度, 形成稳固的受众 群体，提升历史文化信息传播的效能。

其二, 丰富新闻形态, 达到传播形式多样化的目 的。当下的历史文化微信公众号仅有部分公众号使用 短视频新闻、GIF 动图以及 $\mathrm{H} 5$ 新闻等传播样态。因 此, 历史文化传播要以融合新闻的十种新闻样态为核 心, 增强受众之间的互动性, 通过视觉传播吸引用户 眼球，增强历史文化信息的科普传播效果。

\subsection{2. 传播内容}

历史文化类微信公众号的发布内容大致可分为 以下几类: 人文地理、历史文化、历史文化遗产宣传、 景区服务和广告等。多数历史文化资源微信公众号推 送内容以历史文化遗产为中心进行景区宣传, 而针对 历史文化信息科普传播的内容不在信息传播的范围 中, 与文化科普传播关联度不足, 因此, 历史文化类
微信公众号的文章推送应找准主题, 将历史文化信息 的科普传播作为一项重要的传播内容, 充分利用人文 优势和历史优势, 更好的打造优秀历史文化形象。

\subsection{3. 传播效果}

从积极方面来讲, 平台用户基数大, 传播环境稳 定。2020 年, 微信的月活数已达 11.51 亿, 其强大的 活跃性不仅为历史文化传播提供了庞大的用户基数 作为潜在受传者, 同时也创造了持久且稳定的传播环 境，更能加速建立有效的传播机制。

从消极方面来讲, 平台运营互动性弱, 欠缺全方 位的主体互动模式。目前, 微信公众号仅设置留言区 用以实现文章发布主体与订阅者之间的互动, 因此, 应将反馈和互动列为微信运营过程中的关键部分, 鼓 励用户留言, 让受众感受到受重视和被关注, 提升用 户参与度, 同时了解订阅者的兴趣及习惯, 从而及时 准确的调整图文内容、推送时间和频次, 最终提高微 信公众号的影响力。

\section{3. 历史文化类网站分析}

\section{1. 历史文化类网站发展现状}

2015 年 2 月, 习近平总书记在西安市博物馆参 观时强调, “一个博物院就是一所大学校”。而历史文 化类网站, 则是中国数字博物馆的重要表现形式。它 不仅是作为线下博物馆的数字化视觉展现, 同时也打 破了时间和空间的界限, 更有利于推动历史文化知识 的科普传播。

表 2 历史文化类网站现状分析

\begin{tabular}{|l|l|l|l|l|}
\hline $\begin{array}{l}\text { 类 } \\
\text { 别 }\end{array}$ & 主要传播内容 & 标题栏 & 特别版块 & 网页特点 \\
名 & & & & \\
\hline 中国国家 & 以历史与艺术并重， & "征集" & 网上展览 & 以图文结合的形式与社交网站 \\
\hline
\end{tabular}




\begin{tabular}{|c|c|c|c|c|}
\hline 博物馆 & $\begin{array}{c}\text { 集收藏、展览、研 } \\
\text { 究、考古、公共教 } \\
\text { 育、文化交流于一体 } \\
\text { 的综合性博物馆 }\end{array}$ & $\begin{array}{l}\text { "保管" } \\
\text { "研究" } \\
\text { "展览" } \\
\text { "社教" } \\
\text { "文创" }\end{array}$ & $\begin{array}{c}\text { 在线展厅 } \\
\text { 国博讲堂版块 } \\
\text { 公众教育版块 }\end{array}$ & $\begin{array}{c}\text { 的观众进行互动，使展品在虚 } \\
\text { 拟展厅中展示可以通过时代、 } \\
\text { 质地和品类进行检索。 }\end{array}$ \\
\hline $\begin{array}{c}\text { 故宫博物 } \\
\text { 院 }\end{array}$ & $\begin{array}{c}\text { 文物收藏主要来源于 } \\
\text { 清代宫中旧藏，是第 } \\
\text { 一批全国爱国主义教 } \\
\text { 育示范基地。 }\end{array}$ & $\begin{array}{l}\text { "首页" } \\
\text { "导览" } \\
\text { "展览" } \\
\text { "教育" } \\
\text { "探索" } \\
\text { "学术" } \\
\text { "文创" }\end{array}$ & $\begin{array}{c}\text { 中文、英文和青少 } \\
\text { 年三版。青年版以 } \\
\text { 漫画作为主要表现 } \\
\text { 方式。 }\end{array}$ & $\begin{array}{l}\text { 页面字体有中国书法的风格， } \\
\text { 还有中古古代传统纹样，古色 } \\
\text { 古香，连小小的图标设计也具 } \\
\text { 有民族特色。但是让人感觉主 } \\
\text { 次不够明显，主页面花哨了一 } \\
\text { 些，忽略了整体性和统一性。 }\end{array}$ \\
\hline 全历史 & $\begin{array}{l}\text { 通过高度时空化、关 } \\
\text { 联化数据的方式构造 } \\
\text { 及展现数字人文内容， } \\
\text { 尤其是历史知识。 }\end{array}$ & $\begin{array}{c}\text { "国家历史 } \\
\text { 时间轴" } \\
\text { “关系地图" } \\
\text { "时间地图" } \\
\text { "文章" } \\
\text { "画作" } \\
\text { "往期专题" }\end{array}$ & $\begin{array}{l}\text { 全画作 } \\
\text { 全古籍 }\end{array}$ & $\begin{array}{c}\text { 全面向我们展示该时期的整体 } \\
\text { 面貌。提倡用户参与历史系统 } \\
\text { 构建仅加强了用户与产品之间 } \\
\text { 的联系。 }\end{array}$ \\
\hline 国学网 & $\begin{array}{l}\text { 以国学经典书籍的数 } \\
\text { 据整理及研究为主要 } \\
\text { 内容的国学网站。 }\end{array}$ & $\begin{array}{l}\text { "国学宝典" } \\
\text { "国学人物" } \\
\text { "国学书苑" } \\
\text { "国学投稿" } \\
\text { “国学入门" } \\
\text { “国学专题" } \\
\text { "国学产品" }\end{array}$ & $\begin{array}{l}\text { 国学 } 365 \\
\text { 国学资讯 } \\
\text { 诗词情话 }\end{array}$ & $\begin{array}{l}\text { 页面字体主要以繁体字为主， } \\
\text { 页面简洁大方，清晰，对于版 } \\
\text { 块的划分明了。色彩以白色和 } \\
\text { 红色为主色调，字体为绿色。 } \\
\text { 其网页特色不明显，与普通的 } \\
\text { 网站差异小。 }\end{array}$ \\
\hline $\begin{array}{c}\text { 陕西历史 } \\
\text { 博物馆 }\end{array}$ & $\begin{array}{l}\text { 集中于珍藏陕西地区 } \\
\text { 出土的珍贵文物 } 37 \text { 万 } \\
\text { 余件，包括展览时 } \\
\text { 间、博物馆活动等 }\end{array}$ & $\begin{array}{l}\text { "概述" } \\
\text { "展览" } \\
\text { "服务" } \\
\text { “研究" } \\
\text { “活动" } \\
\text { "藏品" } \\
\text { "资讯" }\end{array}$ & $\begin{array}{l}\text { 到馆统计 } \\
\text { 馆内新闻 }\end{array}$ & $\begin{array}{l}\text { 页面色彩主要以红色和黑色为 } \\
\text { 主，以整版的图片展示传播主 } \\
\text { 题。网页导航以陕西博物馆的 } \\
\text { 主要藏品剪影为链接，具有浓 } \\
\text { 厚的历史气息和博物馆特色。 }\end{array}$ \\
\hline $\begin{array}{c}\text { 故宫历史 } \\
\text { 网 }\end{array}$ & $\begin{array}{c}\text { 内容以历史为主，且 } \\
\text { 重点关注中国古代 } \\
\text { 史，以朝代为单位划 } \\
\text { 分历史时间 }\end{array}$ & $\begin{array}{c}\text { “中国历史" } \\
\text { "世界历史" } \\
\text { “历史秘闻" } \\
\text { “历史焦点" } \\
\text { “历史人物" } \\
\text { “战史风云" } \\
\text { “历史传说" } \\
\text { “野史趣闻" } \\
\text { “历史文化" } \\
\text { “考古发现" } \\
\text { “历史旧照" }\end{array}$ & $\begin{array}{l}\text { 历史头条 } \\
\text { 阅读排行榜 } \\
\text { 编辑推荐 }\end{array}$ & $\begin{array}{l}\text { 页面色彩主要以红色和白色为 } \\
\text { 主，与其他的网站相同，网站 } \\
\text { 排版以网格状为主，关键新闻 } \\
\text { 用红色加黑字体进行标注。 }\end{array}$ \\
\hline
\end{tabular}




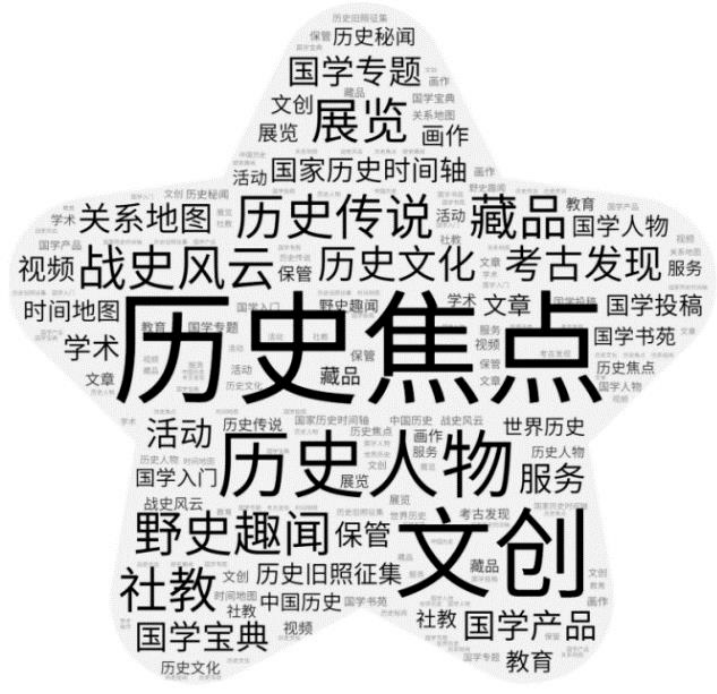

图 2 历史文化类网站标题栏关键词词云图

\section{2. 历史文化类网站传播力研究}

\subsection{1. 传播形式}

其一, 视觉设计要更具美感和表现力。单纯的文 字和图片已经无法满足受众需求, 因此, 视觉表现力 强的审美设计是决定网站运营质量的重要因素之一。 设计团队要能够把握网站页面的整体设计风格, 熟悉 基本框架, 让设计更具目的性和实用性, 文案的编辑 能力要强, 同时要注意简洁明了的网页设计更能拥有 良好的传播效果。

其二，展示形式过于扁平单一，需要虚拟化、多 元化和智能化的表达形式。传播形式的创新性能较大 程度的吸引受众, 培养受众的视觉习惯和兴趣。首先, 诸如网站中的文字、图片、动画等需要规范化、条理 化。其次, 融入摄影、摄像、动画、三维、四维图像 处理技术以及虚拟技术, 将历史文化以新的形式展现 给大众。

\subsection{2. 传播内容}

其一, 文化网站信息的全面性和逻辑性有待加强。
数字博物馆由于其线上展览的制约性和弊端, 重点在 于对藏品的整体性进行展示, 忽略了藏品的细节部分, 其片面化的藏品信息只能让受众从外部感受其魅力, 忽视了其内部的历史文化底蕴。只有通过具有逻辑性 的勾画和重塑, 建立起以数字藏品为中心的一系列的 信息链条, 才能让受众更好地掌握历史知识的脉络。

其二，文化网站的信息针对性不明确。应该为不 同类型的用户提供更为完善并适合的学习与交流资 源, 通过定期统计数据并分析, 可以便捷、准确地跟 踪用户对不同内容的接受情况及评价，同时针对不同 年龄阶段的大众群体, 加入符合各个年龄阶段审美的 多元化元素, 通过对用户进行分层达到更好的传播效 果。

\subsection{3. 传播效果}

从积极层面来讲, 历史文化遗产与网站信息互通, 建立了线上线下的全媒体信息平台。对受众来说，线 上博物馆的建立更能突出数字展览的概念, 能够不断 完善展览展示内容和形式, 加强构建以历史文化遗产 为中心的资源推介信息平台, 打破了展览中的空间限 制和时间限制, 给予受众更独特的展览氛围和视觉体 验。

从消极方面来讲，历史文化教育传播的职能重视 程度欠缺。可以针对不同的年龄阶段做不同风格的学 习模块, 提升受众的参与度。同时历史文化类网站可 以将历史文化游戏融入博物馆知识中, 让受众在获取 信息时, 加强趣味性和互动性, 培养受众在知识探索 当中的创造性和批判性思维。

\section{4. 历史文化类抖音账号分析}

\section{1. 历史文化类抖音账号发展现状}

根据 CNNIC 发布的《第 45 次中国互联网络发展 状况统计数据》, 截至 2020 年 3 月, 中国网络视频 (含 短视频）用户规模达 7.68 亿，占网民整体的 $85.0 \%$ 。 伴随着当前短视频的快速传播, 信息生产更加大众化, 历史文化也获得了创新出新的传播形式, 抖音为代表 的短视频平台对传承历史文化发挥了重要作用。

表 3 历史文化类抖音号现状分析

\begin{tabular}{|c|c|c|c|c|c|c|c|}
\hline 类别 & 传播内容 & $\begin{array}{l}\text { 主 要 发 } \\
\text { 布时间 }\end{array}$ & $\begin{array}{c}\text { 内容形 } \\
\text { 式 }\end{array}$ & $\begin{array}{l}\text { 作品 } \\
\text { 数量 }\end{array}$ & $\begin{array}{c}\text { 价值观输出对 } \\
\text { 传播效果的影响 }\end{array}$ & $\begin{array}{l}\text { 受众 } \\
\text { 特点 }\end{array}$ & $\begin{array}{l}\text { 受众 } \\
\text { 主要 } \\
\text { 区域 }\end{array}$ \\
\hline $\begin{array}{c}\text { 趣谈历 } \\
\text { 史 }\end{array}$ & $\begin{array}{l}\text { "历史" } \\
\text { "助手" } \\
\text { "山海经" } \\
\text { "三国 }\end{array}$ & $\begin{array}{l}16: 00- \\
17: 00\end{array}$ & $\begin{array}{l}\text { 时长> } \\
60 s \text { 为主 } \\
\text { 的短视 } \\
\text { 频 }\end{array}$ & 985 & $\begin{array}{c}\text { 总获赞: } 930.71 \mathrm{w} \\
\text { 平均视频分享量 : } 252 \\
\text { 趣谈历史方式普及冷门历史 } \\
\text { 知识暗含传播者对历史事件 }\end{array}$ & $\begin{array}{l}18-40 \text { 岁 } \\
\text { 男性占比 } 88 \% \\
\text { 活跃时间段 : } \\
\text { 8、12、16 时 }\end{array}$ & $\begin{array}{l}\text { 广东 } \\
\text { 山东 } \\
\text { 江苏 } \\
\text { 四川 }\end{array}$ \\
\hline
\end{tabular}




\begin{tabular}{|c|c|c|c|c|c|c|c|}
\hline & 演义" & & & & 的看法 & & \\
\hline $\begin{array}{l}\text { 央视国 } \\
\text { 家记忆 }\end{array}$ & $\begin{array}{l}\text { “中国"“致 } \\
\text { 敬" } \\
\text { "英雄" } \\
\text { "真贵" }\end{array}$ & $\begin{array}{l}14: 00- \\
17: 00\end{array}$ & $\begin{array}{l}\text { 时长 } \\
16-60 S \\
\text { 为主的 } \\
\text { 短视频 }\end{array}$ & $\begin{array}{l}10 \\
01\end{array}$ & $\begin{array}{c}\text { 总获赞：3.02 亿。 } \\
\text { 平均视频分享量 } 2986 \\
\text { 访谈和历史影片的形式，讲 } \\
\text { 述历史和当今各行各业的故 } \\
\text { 事 }\end{array}$ & $\begin{array}{l}\text { 18-40 岁 } \\
\text { 男性占比 76\% } \\
\text { 活跃时间段： } \\
\text { 08:00-24:00 }\end{array}$ & $\begin{array}{l}\text { 广东 } \\
\text { 江苏 } \\
\text { 四川 } \\
\text { 山东 } \\
\text { 河南 }\end{array}$ \\
\hline $\begin{array}{c}\text { 《祖国》 } \\
\text { 杂志 }\end{array}$ & $\begin{array}{l}\text { "主席"“党 } \\
\text { 史" } \\
\text { "伟人" } \\
\text { "历史" }\end{array}$ & $\begin{array}{l}14: 00- \\
18: 00\end{array}$ & $\begin{array}{c}\text { 时长 > } \\
60 \mathrm{~s} \text { 为主 } \\
\text { 的短视 } \\
\text { 频 }\end{array}$ & 775 & $\begin{array}{c}\text { 总获赞 } 1248.53 \mathrm{w} \\
\text { 平均视频分享量 : } 332 \\
\text { 以剪辑整理历史素材和历史 } \\
\text { 故事讲述党史、军史、革命 } \\
\text { 家、老兵等 }\end{array}$ & $\begin{array}{c}25 \text { 岁以上 } \\
\text { 男性占比 89\% } \\
\text { 活跃时间段 : } \\
\text { 18-19 时 24-01 } \\
\text { 时 }\end{array}$ & $\begin{array}{l}\text { 山东 } \\
\text { 河南 } \\
\text { 江苏 } \\
\text { 四川 } \\
\text { 广东 }\end{array}$ \\
\hline $\begin{array}{c}\text { 历史五 } \\
\text { 千年 }\end{array}$ & $\begin{array}{l}\text { “历史"“助 } \\
\text { 手" } \\
\text { "智慧" } \\
\text { "曾国藩" }\end{array}$ & $\begin{array}{l}18: 00- \\
20: 00\end{array}$ & $\begin{array}{l}\text { 时长 } \\
31-605 \\
\text { 为主的 } \\
\text { 短视频 }\end{array}$ & 476 & $\begin{array}{c}\text { 总获赞 : } 918.84 \mathrm{w} \\
\text { 平均视频分享量 : } 998 \\
\text { 讲述式介绍书籍、人物和战 } \\
\text { 争 }\end{array}$ & $\begin{array}{c}18-40 \text { 岁 } \\
\text { 男性占比 86\% } \\
\text { 活跃时间段： } \\
\text { 5-6 时 }\end{array}$ & $\begin{array}{l}\text { 江苏 } \\
\text { 广东 } \\
\text { 山东 } \\
\text { 河南 }\end{array}$ \\
\hline $\begin{array}{c}\text { 梦涵说 } \\
\text { 历史 }\end{array}$ & $\begin{array}{c}\text { "历史"“助 } \\
\text { 手" } \\
\text { "知识" } \\
\text { "中国" }\end{array}$ & $\begin{array}{l}18: 00- \\
19: 00\end{array}$ & $\begin{array}{l}\text { 时长 > } \\
31 \mathrm{~s} \text { 为主 } \\
\text { 的短视 } \\
\text { 频 }\end{array}$ & 298 & $\begin{array}{c}\text { 总获赞 : } 688.67 \mathrm{w} \\
\text { 平均视频分享量 : } 1221 \\
\text { 以一个小故事为开头讲解一 } \\
\text { 个历史人物或历史故事 }\end{array}$ & $\begin{array}{c}25 \text { 岁以上 } \\
\text { 男性占比 82\% } \\
\text { 活跃时间段： } \\
\text { 21-01 时 }\end{array}$ & $\begin{array}{l}\text { 广东 } \\
\text { 河南 } \\
\text { 江苏 }\end{array}$ \\
\hline $\begin{array}{c}\text { 咩咩爱 } \\
\text { 历史 }\end{array}$ & $\begin{array}{c}\text { "你的"“伟 } \\
\text { 大" } \\
\text { "奋斗" }\end{array}$ & $\begin{array}{l}17: 00- \\
18: 00\end{array}$ & $\begin{array}{c}\text { 时长 > } \\
31 \mathrm{~s} \text { 为主 } \\
\text { 的短视 } \\
\text { 频 }\end{array}$ & 266 & $\begin{array}{c}\text { 总获赞量 : } 5594.67 \mathrm{w} \\
\text { 平均视频分享量 : } 3045 \\
\text { 以冷知识为主要标签，讲解 } \\
\text { 人物为主穿插讲解历史事件 }\end{array}$ & $\begin{array}{c}18-40 \text { 岁 } \\
\text { 男性占比 77\% } \\
\text { 活跃时间段 : } \\
\text { 5、9 时 } \\
18-24 \text { 时 }\end{array}$ & $\begin{array}{l}\text { 广东 } \\
\text { 江苏 } \\
\text { 山东 } \\
\text { 河南 }\end{array}$ \\
\hline $\begin{array}{c}\text { 老王说 } \\
\text { 历史 }\end{array}$ & $\begin{array}{c}\text { “助手"“历 } \\
\text { 史" } \\
\text { "头条" } \\
\text { "百科" }\end{array}$ & $\begin{array}{l}17: 00- \\
19: 00\end{array}$ & $\begin{array}{l}\text { 时长 } \\
31-605 \\
\text { 为主的 } \\
\text { 短视频 }\end{array}$ & 174 & $\begin{array}{c}\text { 总获赞: } 890.64 \mathrm{w} \\
\text { 平均视频分享量 : } 373 \\
\text { 以影视视频为画面讲解，以 } \\
\text { 我国历史人物为主的奇谈野 } \\
\text { 史 }\end{array}$ & $\begin{array}{c}18-40 \text { 岁 } \\
\text { 男性占比 85\% } \\
\text { 活跃时间段： } \\
\text { 5、8、10 时 }\end{array}$ & $\begin{array}{l}\text { 陕西 } \\
\text { 广东 } \\
\text { 江苏 } \\
\text { 山东 } \\
\text { 河南 }\end{array}$ \\
\hline
\end{tabular}

\section{“历史人物”}

“真相”“" “三国演义”“故宫”

“李鸿章”“近代”“传奇”“珍贵记忆”

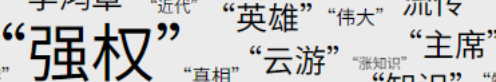

“文化”“伟大”“伟人”“智慧” “知识” “知道” “甲年中日战争”“创始人”“致敬”“主席”“奋斗” “古代”

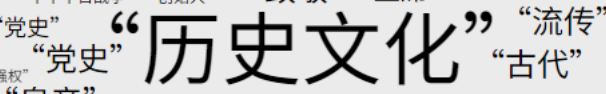

“皇帝”-“曾国蔳”“珍贵记忆”“历史文化”

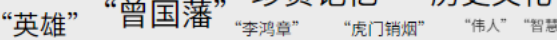

“历史人物” “吉斗“回顾历史”“中国”

“强权”“文化“近代”“虎门销烟”

“强权” “倍”“故宫”“涨知识”

“致敬”“知道” “三国演义”

“皇帝”“传奇”“酥国澫”
图 3 历史文化类抖音账号传播内容关键词词云图

\section{2. 历史文化类抖音账号传播力研究}

\section{2. 1. 受传者}

受众对历史文化类信息多聚焦于表层解码, 不是 对历史的深究。受众通过手机这一媒介接受编码后的 信息, 由于每个人的社会经历和认知能力的不同, 每 个人脑海中解码出来的信息是千差万别的。浮于表面 的历史信息会限制受众的知识储备, 导致对文化内容 产生一定程度的误区。因此要加强对数字技术的使用, 通过大数据画像针对受众进行个性化内容推送, 提升 受众对历史文化内容的理解能力, 完成历史文化信息 的一次到达。 


\subsection{2. 传播内容}

其一，内容同质化和泛娱乐化现象严重。由于抖 音历史文化短视频的特性, 打破了信息输出中的文化 壁垒, 中国历史文化的深层内涵逐渐扩散, 影响力进 一步提升。在电视历史剧的传播过程中, 制作人和导 演将这些客观存在的历史材料进行编码, 形成历史文 化类短视频作品, 导致了同质化现象越来越严重。因 此需将历史文化知识内涵, 建立专业性更强的文化类 视频账号, 加强历史文化信息的深度和广度, 将多元 化的信息内容作为传播过程的重要来源。

其二, 将创新性作为短视频制作的核心要点。能 够在短暂的汶览时间内将受众的吸引力最大化是短 视频制作的关键所在, 它必须要将创新性列为其内容 制作的首要位置。它不仅仅只是单调的历史还原, 更 是通过内容生产者的精心设计和策划。因此, 内容生 产者的历史文化短视频制作要将内容与创意相结合, 真实性与趣味性相结合, 激发受众的视觉感官刺激, 形成深刻的视觉印象。

\subsection{3. 传播效果}

从积极方面来讲, 伴随历史潮流的短视频狂欢满 足了受众消解娱乐的心理。一方面, 让历史大众起来、 平民起来、通俗起来, 让平时高居阁内不食人间烟火 的帝王将相走下神坛, 使人们渴望消解历史的严肃和 深度的心理得到了满足。另一方面, 历史剧避开了为 人们熟知的街头巷尾, 而着重为受众展示宫廷、朝堂 等陌生场景传统历史文化类短视频为人们开辟了一 条通往陌生内容的大门, 深受用户喜爱, 传播效果较 强。

从消极方面来讲, 削弱了对历史文化信息的理性 思考和批判思维。新媒体的出现, 弱化了人们接受信 息的效率, 而造成一种信息灌输的迷局。以抖音为播 送平台的传统历史文化类短视频也存在着同样的问 题。它更多的提供给受众消解, 却极少给予受众机会 去思索借鉴历史。它削弱了青少年批判反思的能力和 理性思维。因此需运用辩证史观看待其传播效果, 有 针对性的提升其传播力。

\section{5. 结论}

历史文化的全媒体传播虽随着时代潮流逐渐形 成了以 “一微一抖一端” 为中心的全媒体传播格局, 但是由于其历史文化信息的特殊性, 需要通过具有创 新性的外在形态和纵深性的内在逻辑, 以历史文化信 息为中心, 以受众为对象进行科普传播, 既要保证用 户知识获取的便捷性和通畅性, 同时又要兼顾历史文 化知识信息的有效到达率, 提升历史文化全媒体平台 的传播力。

\section{项目基金}

本研究为 “中国历史研究院 “中国历史文 化展示与传播研究” 项目 (项目编号: LSYJB2019006）子课题 “历史文化全媒体传播 方式研究”研究成果

\section{REFERENCES}

[1] Guan Minjuan, Deng Jinlian, Huang Xianbing. Design and implementation of virtual tour website for natural and historical cultural heritage of Shaoguan $[\mathrm{J}]$. Computer Knowledge and Technology,2020,16(13):82-84.

[2] Liao Liping. A Brief Discussion on the Form and Content of Traditional Culture Website [J]. Popular Art,2016(19):264-265.

[3]Wang Mei, Tang Shukun, Chen Jingyu. Research on Xuan Paper Culture Website Design Based on HTML5 [J]. Packaging Engineering, 2016, 37(08):143-147.

[4] Ba Yijun. The New Trend of Historical and Cultural Communication from the New Palace Museum [J]. Media,2019(13):59-60.

[5] Zhou Yao. Research on Operation Strategy of Red Culture WeChat Public Account in the New Media Environment -- Taking "Northwest Red Culture Media" as an Example [J]. Research on propagation force,2019,3(01):71.

[6] Zhang Chenggong, Liu Xiaoying. Research on the design of regional history and culture ubiquitous learning content based on WeChat public accounts: A case study of ancient capital Datong [J]. Education Informatization in China, 2016(22): 82-84.

[7] Hao Pengzhan, Zhou Yongdan. Research on the operation status and promotion path of historical and cultural WeChat public accounts in Nanjing, the ancient capital [J]. China Famous Cities, 2020(08):83-91.

[8] Li Xia, Chen Geng. Douyin and popular science: A reanalysis of the communication function of social media [J]. Media,20209 (02) : 49-52. 